Int. J. Electrochem. Sci., 14 (2019) $4280-4287$

International Journal of

ELECTROCHEMICAL

SCIENCE

wWw.electrochemsci.org

\title{
Electrochemical Detection of 2-Methylisoborneol (MIB) Using a Gold Electrode
}

\author{
Jia Du ${ }^{1}, X u$ Peng ${ }^{1}$, Yuting $X u^{1}, L i F u^{1,2, *}$, Di Cao ${ }^{3}$ and Qinghua Liu ${ }^{2, *}$ \\ ${ }^{1}$ College of Materials and Environmental Engineering, Hangzhou Dianzi University, Hangzhou \\ 310018, PR China \\ ${ }^{2}$ Hongze Fishseeds Biotech, Inc. Hongze, Huaian, 223125, PR China \\ ${ }^{3}$ Suzhou Eco-man Biotechnology, Inc. Suzhou, 215141, PR China \\ *E-mail: fuli@hdu.edu.cn, 1103795946@qq.com
}

doi: $10.20964 / 2019.05 .29$

Received: 11 December 2018 / Accepted: 11 February 2019 / Published: 10 April 2019

Odorant substances have been detected in the drinking water of several countries and regions. Although the specific harm of these substances to the human body is not yet clear, they can lead to the decline of drinking-water sensory indicators. In addition, odorants also affect the development of the waterdependent beverage industry and aquaculture industry. Dimethyl isoborneol (2-MIB) is the most common odorant substance that causes soil mildew in drinking water. In this work, for the first time, we first report the electrochemical determination of 2-MIB based on an Au electrode. The electrochemical oxidation of 2-MIB can be achieved due to the excellent conductivity and electrocatalytic property of the Au electrode. The proposed electrochemical sensing method is simple, quick and reliable for 2-MIB determination.

Keywords: 2-MIB; Fishy odor; Gold electrode; Electrochemical sensor; analytical determination

\section{$\underline{\text { FULL TEXT }}$}

(C) 2019 The Authors. Published by ESG (www.electrochemsci.org). This article is an open access article distributed under the terms and conditions of the Creative Commons Attribution license (http://creativecommons.org/licenses/by/4.0/). 